\title{
STUDENT LEARNING STYLES AND CAI AND/OR LECTURING: THE DIFFERENTIAL EFFECTS OF INSTRUCTIONAL METHOD
}

\author{
Carisma Dreyer
}

Potchefstroom University for CHE

A question frequently asked is whether the use of technology is better than the non-use of technology for $L 2$ learning. The purpose of this study is to determine whether instructional method (i.e. lecture vs. CAI vs. combined) affects language achievement differentially for ESL students with dissimilar learning styles. The results of the study indicate that students with dissimilar learning styles achieve differentially as a result of instructional method. The interaction between learning styles and instructional method was statistically significant.

'n Vraag wat baie gevra word is of die gebruik van tegnologie beter is vir tweedetal leerders as die nie-gebruik van tegnologie. Die doel van hierdie studie is om vas te stel of onderrigmetode (lesing of rekenaar gesteunde onderrig of 'n kombinasie van die twee) taalleer uitkomste van Engels tweedetaal leerders met verskillende leerstyle verskillend beïnvloed. Die bevindinge van hierdie studie toon aan dat leerders met verskillende leerstyle verskillend presteer as gevolg van die onderrigmetode. Die wisselwerking tussen leerstyle en onderrigmetode was statisties beduidend.

\section{INTRODUCTION}

There has not yet been a systematic effort in secondary/higher education to understand the ways in which students learn. In contrast, there has been interest in experimenting with technology to improve learning (cf. Bok, 1985). As Bok (1985:17) points out, 'it remains an embarrassing anomaly that professors, who spend so much time evaluating and criticising their institutions, devote so little effort to finding ways to improve their own methods of instruction'. One of the technological solutions that has recently generated much enthusiasm in English Second Language (ESL) teaching is computer-assisted instruction (CAI). Although the few experimental and quasi experimental studies to date often compare CAI to another teaching method, the implicit assumption of these studies has been that CAI makes a difference. However, these traditional comparison studies do not consider whether or not certain teaching methods work better in connection with certain student attributes. No single instructional modality may be optimal for all learners (Yoder, 1994). Little research has been done to identify which learners do best with CAI, which do better with lecturing, or do better with a combination approach. According to Brink (1994), 50\% of the student population is not taught in their preferred style. This lack of research has not stopped language educators from enthusiastically embracing technology. 
The purpose of this study is to determine whether instructional method affects language achievement differentially for ESL students with dissimilar learning styles.

\section{RESEARCH ON COMPUTER-ASSISTED INSTRUCTION AND LEARNING STYLES}

Surveys of computer usage in higher education indicate that lecturers use computers for both research and instructional purposes. The availability of computers in college and university settings has increased dramatically over the past few years with most institutions making resource centres available to the general student population. As a result, use of computer-based instruction as an adjunct to traditional instructional methods is becoming more common. Several distinctions are made between the function of instructional software and extent of use in the instructional process. With regard to extent of use, computer-based learning can be described as primary or adjunct (MacGregor et al., 1988). Primary computer-based instruction provides stand-alone instruction for a course, and is used frequently for distance learning situations. In contrast, adjunct computer-based instruction supplements traditional instructional, and is the type used by university lecturers to complement lectures. Instructional software that provides elaboration of a concept or the practice of concepts previously introduced is likely to be used for adjunct instruction.

The function of courseware can be categorised as drill and practice, tutorial or simulation (Burke, 1982). Drill and practice courseware provides opportunities for students to review concepts covered in class and receive immediate feedback about performance. The ESL PLATO courseware, to be used in this study, is primarily a drill and practice curriculum of lessons in two skill areas: grammar and reading comprehension. The primary motivation at the university level for using software of the type described is to provide more adequate instructional methods and to take advantage of the unique interactional capabilities of computer technology (MacGregor et al., 1988). The combination of effective instruction and savings in instructional time is significant because the time saved can be used for activities not suited to computer presentation.

General findings related to the effectiveness of using the computer as an instructional tool across educational levels indicate that the computer stimulates motivation (Lepper, 1985; Raffini, 1996), can be as effective or superior to traditional instructional approaches (cf. Kearsley, 1977; Paden et al., 1977; Dence, 1980; Avent, 1993), and facilitates faster learning by the student (cf. Murphy \& Appel, 1977; Capper \& Copple, 1985). The effectiveness of computer-based university instruction has been evaluated by a number of researchers. Meta-analyses of these studies indicate computer-based instruction significantly raises students' examination grades, has a moderate effect on students' attitudes toward the subject studied, and reduces the amount of time needed for instruction (cf. Kulik \& Kulik, 1986). Though general in nature the findings of studies clearly indicate that the use of computer-assisted instruction as an adjunct to traditional methods can be a beneficial instructional approach.

One concern related to the use of any instructional method, however, is the possible discriminatory effect of that particular approach in students with specific traits, most notably, different learning styles. Although many researchers have investigated the general effectiveness of specific CAI programs, only a few have carefully examined the 
interactions between CAI and individual learner differences. A question which arises is: Is it possible that students with certain learning styles benefit from CAI while those with other learning styles demonstrate higher achievement via more traditional methods (e.g., the lecture)?

Research into learning style has its roots in the late 19th and 20th centuries. This early research emphasised 'finding the one perceptual mode that would best increase learning or retention' (Keefe, 1987:6). Researchers began to recognise, however, that different learners had different cognitive styles (cf. Messick, 1976). Researchers have attempted to identify and isolate specific traits of learners to describe the unique processes of learning. Learning style theory postulates that students will be motivated to learn and will learn better if taught the way they prefer and will learn better. The underlying assumption is that individual learning preferences will affect performance. The ever-growing quantity of research continues to reinforce one central theme: variations in student learning style can have important implications for the instructional process.

Although many researchers have examined learning style and CAI as separate entities, 'research is just beginning to catch up with the concept of studying the relationships between CAI and learning preferences' (Geisert et al., 1990:298). In a few of these studies, no interaction effects were found (Cordell, 1991; Willett \& Netusil, 1989), but several of them indicated that interactions exist between various learning styles and the relative high achievement of students involved in CAI (Davidson et al., 1992; MacGregor et al., 1988; Post, 1987). These studies have shed some light on the relative effectiveness of CAI approaches for students with a variety of learning styles. However, research investigating the relationship between cognitive style and the effects of CAI on achievement is inconclusive (e.g., Burger, 1985). Hahn (1984) found that field independent learners tend to do equally well with different instructional methods, whereas field dependent college students benefit from CAI. Field independent learners find it easy to detach a perceived item from its given background. Field independence is closely related to classroom learning/activities that involve analysis, attention to details and mastering of exercises, drills and other focused activities (Dreyer, 1992). Field dependence is, conversely, the tendency to be 'dependent' on the total field so that the parts embedded within the field are not easily perceived but instead are 'fused' with the context. Field dependent learners may be more successful in learning the communicative aspects of a second language (Dreyer $e_{t} t$ al., 1996). Although students succeed in learning environments that may be mismatched to their cognitive style, learning may be optimised with a style-instructional match. Tailoring instruction to student's learning style may make students more motivated to learn, although few research studies have been conducted to explore this view. Ester (1995) states that the nature of the interaction between CAI and learning style is quite complex. One conclusion seems clear, however: Further research involving learning styles and instructional approaches is needed to provide the broad base of information necessary to define any general trends with respect to the interaction between $\mathrm{CAI}$ and learning style. 


\section{METHOD OF RESEARCH}

\subsection{Design}

A true experimental design in which the students (first year university students taking English as either a major or as a required subject for degree purposes, for example, law students) were randomly assigned to three treatment groups was used.

\subsection{Subjects}

The accessible population included all first year students taking English as a major subject (ENG 111; $n=62$; academic course focusing on grammar and literature) and students taking English as a subject to fulfil requirements for their respective degrees, for example, law students (ENG 112; $n=41$ part time and $n=83$ full time; practical skills course focusing on reading, writing, speaking and grammar). The treatment groups were made up of students from various mother-tongue backgrounds (e.g. Afrikaans, Tswana and Sotho). The intact classes (i.e. individual students weren't randomly assigned but the whole class, e.g. ENG 111) were randomly assigned to one of the three experimental treatments.

\subsection{Instrumentation}

The following paper-and-pencil tests were used:

- Part 1 of the Style Analysis Survey (SAS) was used to determine the students' sensory preferences for learning (i.e. visual, auditory and hands-on) (Cronbach alpha $=0,76$; content and concurrent validity).

- The Gottschaldt Figures Test (GFT) was used to determine field independence/dependence (KR21 $=0,79)$.

- Beginning (pre-test) and end-of-semester (post-test) language scores were used as measures of language (grammar and reading comprehension) achievement.

- A biographical questionnaire was used to collect information on age, gender, mother tongue, and self-perceptions of proficiency.

\subsection{Data collection procedure}

The students 'intact' (e.g., ENG 112 [full time], ENG 112 [part time] and ENG 111 [full time]) were randomly assigned to one of the three experimental groups (e.g. lecture, CAI, and a combined lecture-CAI). The lecture group received 'traditional' grammar and comprehension lessons by means of 'lecturing' by the lecturers. The CAI group received traditional classroom grammar and reading comprehension lessons by means of PLATO, while the combination lecture-CAI group received traditional classroom lectures supplemented by lessons using PLATO. The lecture group and the combination group were taught by the same lecturer. The content (e.g., concord, tenses, prepositions, direct and indirect speech, pronouns, adjectives and adverbs) covered in the lecture treatment group and that covered in the CAI treatment group were identical. Students in the lecture treatment group were also given similar drill and practice activities/exercises to that provided by the PLATO courseware. The treatment covered a fourteen-week semester. All students wrote the pre-test and post-test. These tests focused only on grammar and reading comprehension. In addition to these language tests, the following tests (SAS, GFT and the biographical questionnaire) were administered during the first scheduled language period. 


\subsection{Analysis}

The data were analysed by using the STATISTICA software package. A two-way analysis of covariance (ANCOVA) was calculated to determine the interaction between instructional method and learning styles. The pre-test scores served as the covariate and the post-test scores as the dependent variable. All of the fundamental assumptions upon which ANCOVA is based, including homogeneity of regression, were met. Follow-up post-hoc Tukey HSD tests were calculated to determine where the differences in the mean performances (post-test) occurred. Cohen's (1977) effect size d was used to determine whether the effect was practically significant. Cohen uses the following scales for the $d$ values:

$\mathrm{d}=0,2$ (small effect size)

$\mathrm{d}=0,5$ (medium effect size)

$\mathrm{d}=0,8$ (large effect size)

\section{RESULTS AND DISCUSSION}

The results of the post-hoc Tukey tests for sensory preferences per instructional method are reported in Table 1 . Overall the results indicate that all students (visual, auditory and hands-on) showed a bigger mean gain score (i.e. post-test minus pre-test) in the combined class (groups 3,6 and 9) than in the lecture or CAI classes. The Tukey tests indicate the following main trends: the visual students in the CAI class (group 2) performed statistically significantly $(p<0,05)$ better on the language achievement test than did the visual students in the lecture class (group 1) (medium effect size $d=0,59$ ); the auditory students in the lecture class performed statistically significantly $(p<0,05)$ better on the language achievement test than did the auditory students in the CAI class (large effect size $\mathrm{d}=1,13$ ). The hands-on students performed slightly better in the lecture class than in the CAI class (small effect size $d=0,29$ ). The hands-on students, however, seemed to gain the most from a combined instructional method. 
Table 1: Post-hoc Tukey HSD tests for sensory preferences per instructional method

\begin{tabular}{|c|c|c|c|c|c|c|c|}
\hline Treatment & $\mathbf{N}$ & $\begin{array}{l}\text { Pretest } \\
M\end{array}$ & $\begin{array}{l}\text { Pretest } \\
\text { SD } \\
\end{array}$ & $\begin{array}{l}\text { Posttest } \\
\text { M }\end{array}$ & $\begin{array}{l}\text { Posttest } \\
\text { SD }\end{array}$ & $\begin{array}{l}\text { M gain } \\
\text { score }\end{array}$ & Tukey \\
\hline 1 & 39 & 59,02 & 4,28 & 60,46 & 5,16 & 1,44 & $\begin{array}{l}2,3,4,6 \\
7,9^{*}\end{array}$ \\
\hline 2 & 31 & 62,12 & 4,28 & 64,61 & 7,08 & 2,49 & $1,4,5,8^{*}$ \\
\hline 3 & 55 & 61,12 & 6,27 & 64,21 & 6,05 & 3,11 & $1,4,8^{*}$ \\
\hline 4 & 13 & 65,61 & 6,66 & 68,61 & 7,03 & 3,00 & $\begin{array}{l}1,2,3,5,6 \\
7,8,9^{*}\end{array}$ \\
\hline 5 & 3 & 61,33 & 4,61 & 60,66 & 6,11 & $-0,67$ & $2,4^{*}$ \\
\hline 6 & 11 & 59,63 & 8,47 & 62,72 & 8,31 & 3,09 & $1,4^{*}$ \\
\hline 7 & 10 & 61,30 & 7,70 & 62,90 & 8,64 & 1,60 & $1,4^{*}$ \\
\hline 8 & 7 & 59,71 & 3,54 & 60,42 & 2,81 & 0,71 & $2,3,4^{*}$ \\
\hline 9 & 17 & 59,76 & 5,43 & 62,88 & 5,21 & 3,12 & $1,4^{*}$ \\
\hline
\end{tabular}

Key:

$\mathbf{N}$ - number of subjects in group

$\mathbf{M}$ - mean

SD - standard deviation

\section{Treatment}

1 - Visual lecture

2 - Visual CAI

3 - Visual combined

4- Auditory lecture

5 - Auditory CAI

6- Auditory combined

7 - Hands-on lecture

8 - Hands-on CAI

9 - Hands-on combined

\section{Statistical significance}

$* \mathrm{p}<0,05$

Sensory preference refers to the physical, perceptual learning channels through which the student learns most comfortably (cf. Oxford et al., 1991). Visually oriented students need a great deal of visual stimulation (e.g. computers), while the auditory students are more comfortable with lectures. The hands-on students like manipulative and three-dimensional materials that are touchable and moveable (cf. Dreyer, 1998). The results of this study, therefore, seem to indicate that lecturers/teachers need to take cognisance of their students' different learning styles and also need to learn how to accommodate these differences by means of using a variety of instructional methods as well as exercises and activities. A student's perceptual strengths and weaknesses are extremely important for no matter how motivated a student might be, inability to absorb and retain through an inappropriate sense tends to dampen motivation, and, certainly, inhibits achievement.

Figure 1 graphically presents the interaction between sensory preferences and instructional method. The significance of the learning style by treatment interaction indicates that students with dissimilar learning styles achieve differentially as a result of instructional methods. The auditory students did statistically significantly better in the lecture class (cf. 
Table 1), the visual students did statistically significantly better in the CAI class (cf. Table 1), but on average the combined method seemed to be to the advantage of all students.

Figure 1: Interaction between learning styles (sensory preferences) and instructional methods

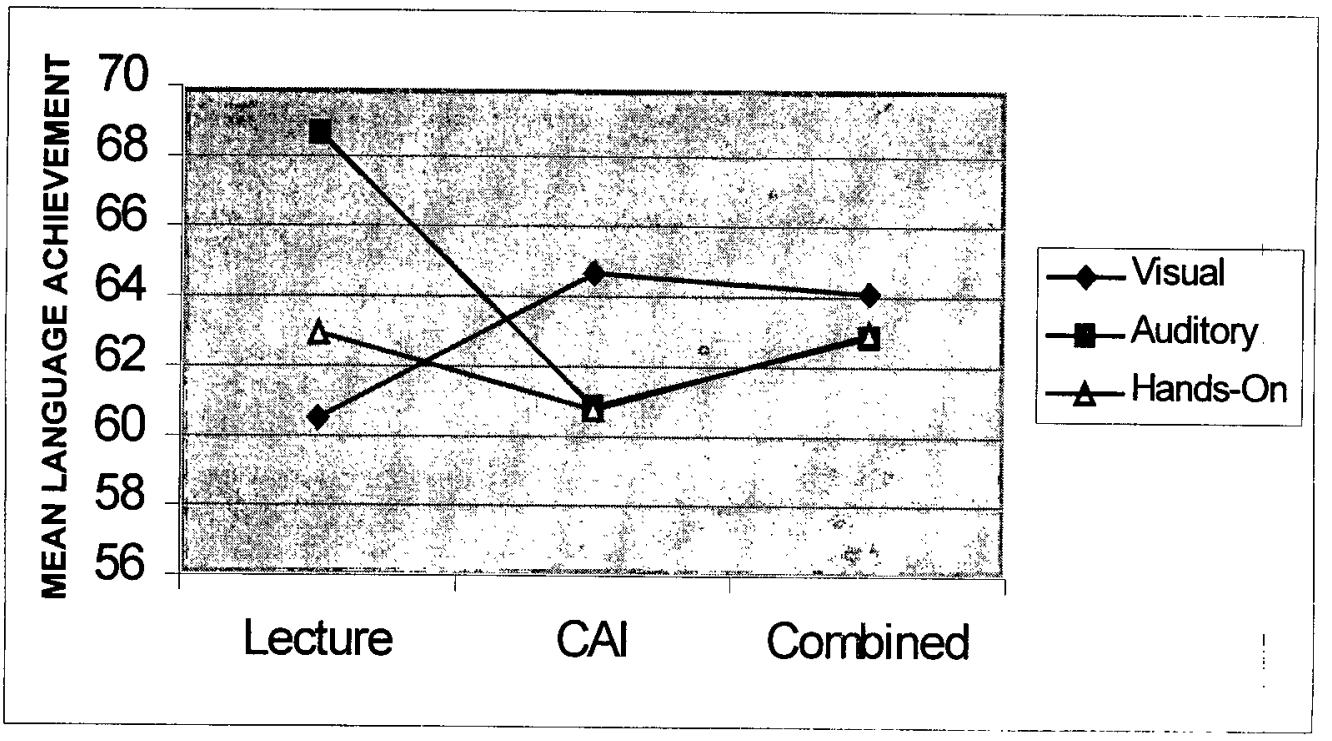

The results of the post-hoc Tukey tests for field dependent and field independent learning styles per instructional method (i.e. treatment) are reported in Table 2. Overall the results indicate that all students (field dependent and field independent) showed a bigger mean gain score (i.e. post-test minus pre-test) in the combined class (groups 3 and 6) than in the CAI classes. The Tukey tests indicate the following main trends: the field dependent students in the CAI class (group 2) performed statistically significantly $(p<0,05)$ better on the language achievement test (post-test) than did the field dependent students in the lecture class (group 1) (medium effect size $d=0,56$ ); the field independent students in the lecture class (group 4) performed statistically significantly $(p<0,05)$ better on the language achievement test than did the field independent students in the CAI class (group 5) (large effect size $d=0,88$ ). 
Table 2: Post-hoc Tukey tests for field dependent (global) and field independent (analytic) learning styles per instructional method

\begin{tabular}{|l|l|l|l|l|l|l|l|}
\hline Treatment & $\mathbf{N}$ & $\begin{array}{l}\text { Pretest } \\
\mathbf{M}\end{array}$ & $\begin{array}{l}\text { Pretest } \\
\text { SD }\end{array}$ & $\begin{array}{l}\text { Posttest } \\
\text { M }\end{array}$ & $\begin{array}{l}\text { Posttest } \\
\text { SD }\end{array}$ & $\begin{array}{l}\text { M gain } \\
\text { score }\end{array}$ & Tukey \\
\hline 1 & 44 & 59,43 & 6,00 & 60,59 & 6,78 & 1,16 & $2,3,4^{*}$ \\
\hline 2 & 32 & 61,93 & 6,42 & 64,37 & 6,32 & 2,44 & $1,4,5,6^{*}$ \\
\hline 3 & 61 & 61,06 & 6,66 & 64,24 & 6,42 & 3,18 & $1,4,5,6^{*}$ \\
\hline 4 & 18 & 64,05 & 4,63 & 67,38 & 4,59 & 3,33 & $1,2,3,5,6^{*}$ \\
\hline 5 & 9 & 60,66 & 7,69 & 60,88 & 7,32 & 0,22 & $2,3,4^{*}$ \\
\hline 6 & 22 & 59,50 & 5,57 & 62,36 & 5,39 & 2,86 & $2,3,4^{*}$ \\
\hline
\end{tabular}

Key:

$\mathrm{N}$ - number of subjects

$\mathrm{M}$ - mean

$\mathrm{SD}$ - standard deviation

Treatment

1 - Field dependent lecture

2 - Field dependent CAI

3 - Field dependent combined

4 - Field independent lecture

5 - Field independent CAI

6 - Field independent combined
Statistical significance

$* \mathrm{p}<0,05$

Some students (including certain field independent learners) need to have a very structured basis for their L2 learning, and many of these students might not be comfortable 'creating' communicatively with the language unless and until they can use logical reasoning to analyse the language. Such students often prefer explicit feedback on grammatical accuracy. Computer programs with traditional L2 drills and analytic puzzles allow these students to do the exercises that they need for developing precision, accuracy, and analytical understanding.

On the other hand, some field dependent students might be able to jump directly into communicative activities, assisted by technology or not, without the compelling personal need for analysis and accuracy. Instead of explicit feedback on grammatical precision, such students often prefer contextualised clues or indirect suggestions about how to use forms appropriately (Oxford, 1993).

Figure 2 graphically illustrates the interaction between field independence/dependence and instructional method. The significance of the learning style by treatment interaction indicates that students with dissimilar learning styles achieve differentially as a result of instructional methods. The field independent students did statistically significantly better in the lecture class (cf. Table 2), while the field dependent students did statistically significantly better in the CAI class (cf. Table 2). Overall it seems as if a combined method might be to the advantage of all students. 
Figure 2: Interaction between learning styles (field independence/dependence) and instructional methods

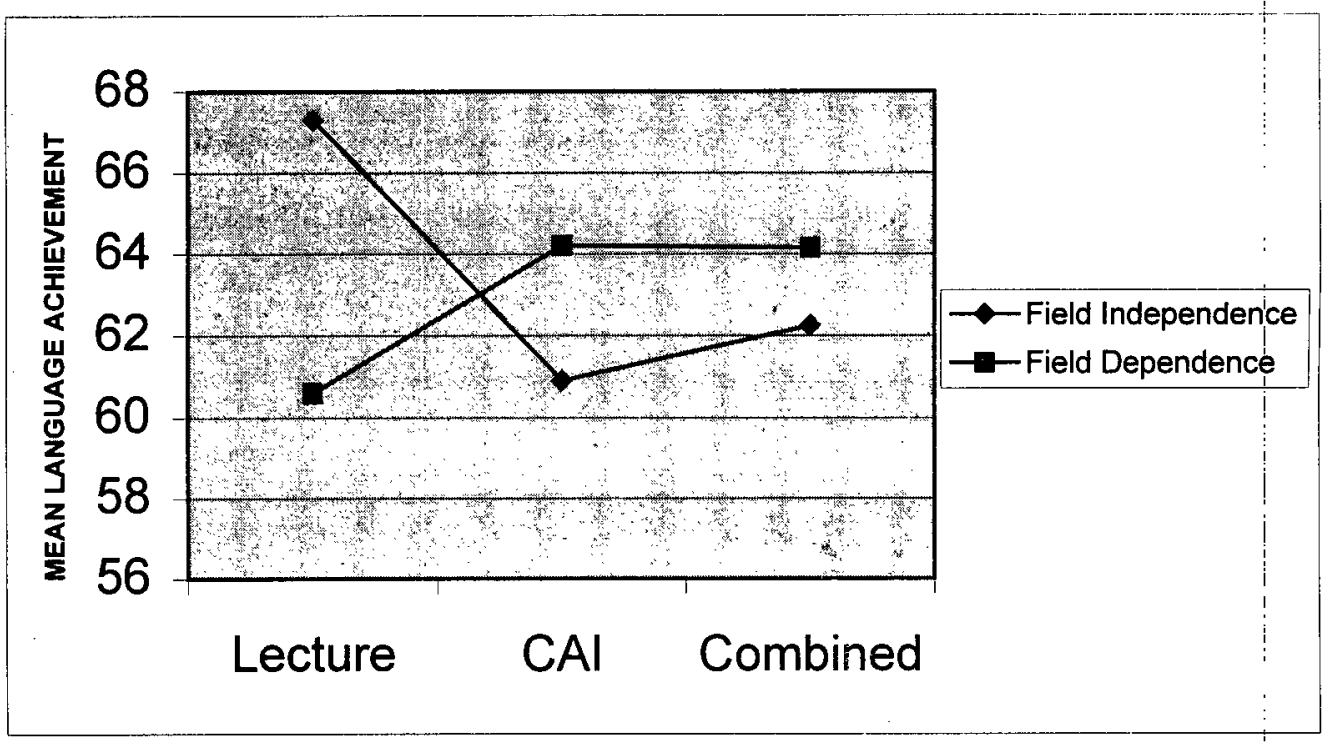

A summary of the two-way ANCOVA results for main effects and the interaction between sensory preferences and instructional method appears in Table 3 . The results indicate a statistically significant interaction $(p<0,01)$ between learning style and treatment.

Table 3: Summary of ANCOVA results for sensory preferences and instructional method

\begin{tabular}{|l|l|l|l|l|l|l|l|}
\hline Source & df Effect & MS Effect & df Error & MS Error & F-ratio & p-level \\
\hline Main effects & & & & & & & \\
\hline Style & 2 & 4,60 & 176 & 4,12 & 1,11 & n.s. & \\
\hline Treatment & 2 & 35,63 & 176 & 4,12 & 8,63 & 0,001 & \\
\hline Interaction & & & & & & & 0,01 \\
\hline LSxTrmt & 4 & 16,43 & 176 & 4,12 & 3,98 & \\
\hline
\end{tabular}

Key:

Style - learning styles

Treatment - lecture, CAI and combined

LSx Trmt - Interaction between learning style and treatment

A summary of the two-way ANCOVA results for main effects and the interaction between field dependence/independence and instructional method appears in Table 4. The results indicate a statistically significant interaction $(p<0,0001)$ between learning style and treatment. 
Table 4: Summary of ANCOVA results for field dependence/independence and instructional method

\begin{tabular}{|l|l|l|l|l|l|l|}
\hline Source & df Effect & MS Effect & df Error & MS Error & F & p-level \\
\hline Main effects & & & & & & \\
\hline Style & 1 & 0,28 & 179 & 3,86 & 0,07 & n.s. \\
\hline Treatment & 2 & 27,25 & 179 & 3,86 & 7,04 & 0,01 \\
\hline Interaction & & & & & & \\
\hline LSxTrmt & 2 & 52,42 & 179 & 3,86 & 13,55 & 0,0001 \\
\hline
\end{tabular}

Key:

Style - learning styles

Treatment - lecture, CAI and combined

LSxTrmt - Interaction between learning style and treatment

Overall the results indicate that students with a visual learning style and/or a field dependent learning style benefit from computer-assisted instruction, while students with an auditory learning style and/or a field independent learning style benefit from receiving instruction via a lecturing method, and hands-on students seem to prefer a variety (i.e. a combination) of instructional methods. These results seem to be consistent with the results found in other studies (cf. Hahn, 1984; MacGregor et al., 1988). The results do, however, contrast with Martini's (1986) findings, which indicated consistently higher achievement for all learners when exposed to CAI. The results, therefore, indicate that the matching or mismatching of student learning styles with instructional methods has important implications for student achievement. It is important, however, to remember that subject matter as well as dimensions of learning style interact with instructional methods in unique ways.

The question is not, therefore: 'Is use of technology better than non-use of technology for L2 learning?'The question should rather be expanded to include: 'Which forms of technology enhance L2 learning (a) with reference to which broad educational goals, (b) with application to which language skills and subskills, (c) for which kinds of learners, (d) with which kinds of teachers, and (e) in what social and physical environments?' (Oxford et al., 1999:3). Integrating technology throughout language curricula can be considered a 'multimodal teaching strategy'. Many different techniques are employed to meet the learning needs of a varied student population. The key to promoting improved learning appears to lie in how effectively the medium is exploited in the teaching and learning situation.

\section{IMPLICATIONS FOR L2 TEACHER TRAINING}

Pre- and in-service teacher training should address L2 teachers' technology skills and attitudes toward technology. Negativity and indifference must be overcome before teachers can improve their technology skills. To deal with such attitudes, teachers should learn ways in which technology can help them improve their language instruction. Technology is motivational, but it should not become a crutch. If a teacher has a boring and monotonous teaching style technology will not save him/her (Anonymous teacher, 1997).

Teacher training should encompass not just computer use but should also deal, when necessary, with using overhead projectors, audiotapes, and videotapes effectively. 
Teachers will also need 'refresher' courses on effective teaching/lecturing, especially if the requirements for Outcome-Based Education (OBE) are to be met. Teachers will need to learn how to integrate technology within their daily lesson structures. Teachers should also learn which cognitive styles fare best with which kind of classroom activities and with which technological applications. Teachers should also develop competence in teaching students how to use technology, so that technology-assisted instruction becomes a vehicle for meaningful learning, not just an exercise in operating software or hardware or a trivial encounter with noise and images. The goal of teacher training should be to empower teachers to make intelligent choices, so that their students can learn more effectively through a variety of media.

\section{CONCLUSION}

An understanding of the way students learn is an important factor in improving educational opportunities for students. No single instructional modality may be optimal for all students; therefore, an awareness of individual learner characteristics and their association with learning outcomes is essential. Computer-assisted instruction holds significant potential for language instruction. If used properly, technology can interest and motivate learners, expand access to a greater number of learners, provide flexibility of instruction, and develop learners' competence and expertise in certain aspects of language. However, technology is not a panacea that suddenly transforms all learning. The effectiveness of educational technology depends on how it is employed to meet educational goals for particular kinds of students in specific language learning environments.

Further exploration and clarification of the relationship between computer-assisted instruction and students with different cognitive characteristics should contribute to the knowledge required to develop optimal learning environments as well as a better understanding of the human-machine teaching relationship relative to student achievement.

\section{REFERENCES}

ANONYMOUS HIGH SCHOOL TEACHER. 1997. Unpublished paper. Tuscaloosa, AL: University of Alabama.

AVENT, JH. 1993. A study of language learning achievement between students using the traditional language learning laboratory and students using computer-assisted language learning courseware. Dissertation Abstracts International, 54(10):3354A.

BOK, D. 1985. Looking into education's high-tech future. EDUCOM Bulletin, 17:2-10.

BRINK, H. 1994. Individual differences in learning or cognitive style. Journal for Vocational and Specialized Education, 143:13-16.

BURGER, K. 1985. Computer-assisted instruction: Learning style and academic achievement. Journal of Computer-Based Instruction, 12(1):21-22. 
BURKE, RL. 1982. CAI sourcebook: Background and procedures for CAI in Educational and Industrial Training. Englewood Cliffs, NJ.: Prentice-Hall.

CAPPER, J. AND C COPPLE. 1985. Computer use in education: Research review and instructional implications. Washington, DC: Center for Research into Practice.

COHEN, J. 1977. Statistical power analysis for the behavioural sciences. Revised ed. New York, NY.: Academic Press.

CORDELL, B. 1991. A study of learning styles and CAI. Computers and Education, 16(2):175-183.

DAVIDSON, GV, WC SAVENYE \& KB ORR. 1992. How do learning styles relate to performance in a computer applications course. Journal of Research on Computing in Education, 24(3):348-358.

DENCE, M. 1980. Toward defining the role of CAI: A review. Educational Technology, 20(11):50-54.

DREYER, C. 1992. Learner variables as ; predictors of ESL proficiency. Potchefstroom. (Unpublished Ph.D. dissertation).

DREYER, C, DP WISSING \& MP WISSING. 1996. The relationship between cognitive styles and pronunciation accuracy in English as a second language. South African Journal of Linguistics, Supplement 34:37-62.

DREYER, C. 1998. Teacher-student style wars in South Africa: The silent battle. System, 26:115-126.

ESTHER, DP. 1995. CAI, lecture and student learning style: The differential effects of instructional method. Journal of Research on Computing in Education, 27(2):129140.

GEISERT, G, R DUNN \& R SINATRA. 1990. Reading, learning styles, and computers. Journal of Reading, Writing and Learning Disabilities International, 6(3):297305.

HAHN, JS. 1984. An exploratory study of the relationship between learner cognitive styles and three different teaching methods used to teach computer literacy with the Pittsburgh information retrieval system. International Journal of Instructional Media, 11(2):147-158.

KEARSLEY, GP. 1977. The cost of CAI: A matter of assumption. AEDS Journal, 10(3):100-110.

KEEFE, J. 1987. Learning style: Theory and practice. Reston, VA. : National Association of Secondary School Principals.

KULIK, C-LC. AND JA KULIK. 1986. Effectiveness of computer-based education in colleges. AEDS Journal, 19(2-3):81-108. 
LEPPER, MR. 1985. Microcomputer in education: Motivational and social issues. American Psychologist, 40:1-18.

MacGREGOR, SK, LZ SHAPIRO \& R NIEMIEC. 1988. Effects of a computer-augmented learning environment on math achievement for students with differing cognitive style. Journal of Educational Computing Research, 4(4):453-565.

MARTINI, M. 1986. An analysis of the relationships between and among CAI, learning style perceptual preferences, attitudes, and the science achievement of seventh grade students in a suburban New York school district. Dissertation Abstracts International, 47:877A.

MESSICK, S (ed.). 1976. Individuality in learning. San Francisco, Ca.: Jossey-Bass.

MURPHY, RT. AND LR APPEL. 1977. Evaluation of the Plato IV computer-based education system in the community college. Princeton, N.J.: Educational Testing Service.

OXFORD, RL. 1993.Intelligent computers for language learning: The view from language acquisition and instructional methodology. Computer-Assisted Language Learning, 6(2):173-179.

OXFORD, RL, M EHRMAN \& RZ LAVINE. 1991. Style wars: Teacher-student style conflicts in the language classroom. In Magnan SS (ed), Challenges in the $1990 \mathrm{~s}$ for college foreign language programs. Boston, MA.: Heinle \& Heinle.

OXFORD, RL, Y RIVERA-CASTILLO, C FEYTEN \& J NUTTA. 1999. Computers and more: Creative uses of technology for learning a second or foreign language. (http://www.insa-lyon.fr/departements/CDRL/computers.html).

PADEN, DW, BR DALGAARD \& MD BARR. 1977. A decade of computer-assistèd instruction. Journal of Economic Education, 9(4):14-20.

POST, P. 1987. The effect of field independence/field dependence on CAI achievement. Journal of Industrial Teacher Education, 25(1):60-67.

RAFFINI, JP. 1996. 150 ways to increase intrinsic motivation in the classroom. Boston: Allyn \& Bacon.

WILLETT, B. AND A NETUSIL. 1989. Music computer drill and learning styles at the 4th grade level. Journal of Research in Music Education, 37:219-229.

YODER, ME. 1994. Preferred learning style and educational technology. Nursing and Health Care, 15(3):128-132. 